11. Renger G in Photosynthetic Oxygen Evolution (ed. Metzner, H.) 229-248 (Academic, London, 1978).

12. Clausen, J., Debus, R. J. \& Junge, W. Time-resolved oxygen production by PSII: Chasing chemical intermediates. Biochim. Biophys. Acta 1655, 184-194 (2004).

13. Babcock, G. T., Blankenship, R. E. \& Sauer, K. Reaction kinetics for positive charge accumulation on the water side of chloroplast photosystem II. FEBS Lett. 61, 286-289 (1976).

14. Dekker, J. P., Plijter, J. J., Ouwehand, L. \& van Gorkom, H. J. Kinetics of manganese redox transitions in the oxygen evolving apparatus of photosynthesis. Biochim. Biophys. Acta 767, 176-179 (1984).

15. Renger, G. \& Weiss, W. Studies on the nature of the water oxidizing enzyme. III. Spectral characterization of the intermediary redox states in the water-oxidizing enzyme system Y. Biochim. Biophys. Acta 850, 184-196 (1986).

16. Saygin, Ö. \& Witt, H. T. Optical characterization of intermediates in the water-splitting enzyme system of photosynthesis-possible states and configurations of manganese and water. Biochim. Biophys. Acta 893, 452-469 (1987).

17. Haumann, M., Bögershausen, O., Cherepanov, D. A., Ahlbrink, R. \& Junge, W. Photosynthetic oxygen evolution: H/D isotope effects and the coupling between electron and proton transfer during the redox reactions at the oxidizing side of photosystem II. Photosynth. Res. 51, 193-208 (1997).

18. Hundelt, M., Hays, A. M., Debus, R. J. \& Junge, W. Oxygenic photosystem II: the mutation D1-D61N in Synechocystis sp. PCC 6803 retards S-state transitions without affecting electron transfer from $\mathrm{Y}_{\mathrm{Z}}$ to $\mathrm{P}_{680}^{+}$. Biochemistry 37, 14450-14456 (1998).

19. Karge, M., Irrgang, K. D. \& Renger, G. Analysis of the reaction coordinate of photosynthetic water oxidation by kinetic measurements of $355 \mathrm{~nm}$ absorption changes at different temperatures in photosystem II preparations suspended in either $\mathrm{H}_{2} \mathrm{O}$ or $\mathrm{D}_{2} \mathrm{O}$. Biochemistry 36, 8904-8913 (1997).

20. Rappaport, F., Blanchard-Desce, M. \& Lavergne, J. Kinetics of electron transfer and electrochromic change during the redox transition of the photosynthetic oxygen-evolving complex. Biochim. Biophys. Acta 1184, 178-192 (1994).

21. Clausen, J. et al. Photosynthetic water oxidation: Mutations of D1-Glu189K, R and Q of Synechocystis sp. PCC6803 are without any influence on electron transfer rates at the donor side of photosystem II. Biochim. Biophys. Acta 1506, 224-235 (2001).

22. Lavergne, J. Improved UV-visible spectra of the S-transitions in the photosynthetic oxygen-evolving system. Biochim. Biophys. Acta 1060, 175-188 (1991).

23. Dekker, J. P. in Manganese Redox Enzymes (ed. Pecoraro, V. L.) 85-104 (VCH Publishers, New York, 1992).

24. Haumann, M., Drevenstedt, W., Hundelt, M. \& Junge, W. Photosystem II of green plants: Oxidation and deprotonation of the same component (histidine?) on $\mathrm{S}_{1}{ }^{*} \rightarrow \mathrm{S}_{2}{ }^{*}$ in chloride depleted centers as on $\mathrm{S}_{2} \rightarrow \mathrm{S}_{3}$ in controls. Biochim. Biophys. Acta 1273, 237-250 (1996).

25. Rappaport, F. \& Lavergne, J. Coupling of electron and proton transfer in the photosynthetic water oxidase. Biochim. Biophys. Acta 1503, 246-259 (2001).

26. Jahns, P., Lavergne, J., Rappaport, F. \& Junge, W. Stoichiometry of proton release during photosynthetic water oxidation: a reinterpretation of the response of Neutral red leads to a noninteger pattern. Biochim. Biophys. Acta 1057, 313-319 (1991).

27. Lavergne, J. \& Junge, W. Proton release during the redox cycle of the water oxidase. Photosynth. Res. 38, 279-296 (1993)

28. Junge, W., Haumann, M., Ahlbrink, R., Mulkidjanian, A. \& Clausen, J. Electrostatics and proton transfer in photosynthetic water oxidation. Phil. Trans. R. Soc. Lond. B 357, 1407-1417 (2002).

29. Beck, W. F., de Paula, J. C. \& Brudvig, G. W. Active and resting state of the O2-evolving complex of Photosystem II. Biochemistry 24, 3035-3043 (1985).

30. Klimov, V. V., Allakhverdiev, S. I., Demeter, S. \& Krasnovsky, A. A. Photoreduction of pheophytin in the photosystem II of chloroplasts with respect to the redox potential of the medium. Dokl. Akad. Nauk SSSR 249, 227-230 (1979).

Supplementary Information accompanies this paper on www.nature.com/nature.

Acknowledgements We thank $\mathrm{H}$. Kenneweg for technical assistance, $\mathrm{H}$. Heine for advice on the construction of the pressure cell, R. Debus for cooperation on Synechocystis, and R. Ahlbrink and A. Mulkidjanian for discussions and help. This work was financially supported by the Deutsche Forschungsgemeinschaft, the Fonds der Chemischen Industrie and the Land Niedersachsen.

Competing interests statement The authors declare that they have no competing financial interests.

Correspondence and requests for materials should be addressed to W.J. (junge@uos.de) addendum

\section{Measuring fast neutrons in Hiroshima at distances relevant to atomic-bomb survivors}

\section{T. Straume, G. Rugel, A. A. Marchetti, W. Rühm, G. Korschinek, J. E. McAninch, K. Carroll, S. Egbert, T. Faestermann, K. Knie, R. Martinelli, A. Wallner, C. Wallner, S. Fujita ${ }^{1}$, K. Shizuma ${ }^{2}$, M. Hoshi ${ }^{3}$} \& H. Hasai ${ }^{4}$

${ }^{1}$ Department of Statistics, Radiation Effects Research Foundation, 5-2 Hijiyama Park, Minami-ku, Hiroshima 732-0815, Japan

${ }^{2}$ Quantum Energy Applications, Graduate School of Engineering, Hiroshima

University, Higashi-Hiroshima 739-8527, Japan

${ }^{3}$ International Radiation Information Center, Research Institute for Radiation, Biology and Medicine, Hiroshima University, 1-2-3 Kasumi, Minami-ku Hiroshima 734-8553, Japan

${ }^{4}$ Hiroshima Kokusai Gakuin University, 6-20-1 Nakano, Aki-ku, Hiroshima 739-0321, Japan

We wish to clarify misunderstandings created by our Letter on the measurement of Hiroshima fast neutrons ${ }^{1}$. Our measurements were partly made within the framework of (and contributed to) a comprehensive reassessment of A-bomb dosimetry conducted by the Joint US-Japan Working Group that produced the new RERF DS02 Dosimetry System, soon to be published ${ }^{2,3}$. Also, our speculation" concerning a "slightly underestimated height-of-burst (HOB) for the Hiroshima bomb" does not imply that the HOB should be changed based solely on the ${ }^{63} \mathrm{Ni}$ measurements. Although our work provides direct information on dose-relevant fast-neutron fluence, it should not be construed to be the sole basis for resolution of the Hiroshima neutron discrepancy that had been reported for thermal neutrons. The original authors were not fully aware of the scientific input of the copper sampling in Hiroshima and wish to remedy this here by extending the author list and by acknowledging additional support from Japanese funding agencies (Grants-in-Aid for Scientific Research B and C of the Japan Ministry of Education, Culture, Sports, Science and Technology for support and the Radiation Effects Research Foundation (RERF) in Hiroshima for the copper sampling effort).

1. Straume, T. et al. Measuring fast neutrons in Hiroshima at distances relevant to atomic-bomb survivors. Nature 424, 539-542 (2003).

2. Cullings, H. M. \& Fujita, S. The way to DS02: resolving the neutron discrepancy. RERF Update 14, 17-23 (2003).

3. DS02: A New Dosimetry System for A-Bomb Survivor Studies Joint Senior Review Group Report on DS02 〈http://tis.eh.doe.gov/health/ihp/japan/DS02.pdf〉 (March 2003). 